\title{
EDITORIAL
}

\section{Learning from aftercare to improve acute care}

\author{
Timothy S. Walsh ${ }^{1,2,3^{*}}$ (1) and Ruth Endacott ${ }^{4,5}$
}

(0) 2019 Springer-Verlag GmbH Germany, part of Springer Nature

Only a few decades ago, intensive care medicine was exclusively viewed as a speciality that used technology to support the organs of critically ill patients who otherwise were almost certain to die from their precipitating illness or its complications. Much has changed. We still provide multiple organ support, and strive to underpin this with high-quality evidence. However, as a speciality we recognise that our care should not necessarily end at the ICU door when our patients are discharged, typically to the care of wide-ranging medical specialists scattered across acute hospitals.

A cynic might ask why the ICU team needs to become involved in 'ICU aftercare', but there are logical and practical reasons why our specialty should drive this agenda. Multiple cohort studies have demonstrated a burden of physical, psychological, and cognitive impairments, which many call the 'post intensive care syndrome', that are prevalent among ICU survivors irrespective of the triggering critical illness [1, 2]. ICU survivors experience substantially reduced quality of life compared to the general population, lose quality-adjusted life years, and have high ongoing healthcare costs [3, 4]; as such it makes economic sense to find interventions to improve recovery after the expensive investment in an ICU stay. Patients and their carers also tell us that research to find out 'How can patients and their families be best supported as they start living at home again?' is a priority for them, and ranks higher than most of the science and technology research we undertake in ICU [5]. Finally, and perhaps most important, unless we lead this challenge who else will?

\footnotetext{
*Correspondence: twalsh@staffmail.ed.ac.uk

${ }^{1}$ Chair of Critical Care, Edinburgh University, Edinburgh, UK

Full author information is available at the end of the article
}

After patients leave our care their journey is characterised by multiple service transitions, and a progressive dilution of knowledge and understanding among caring healthcare professionals about what happened to their patient in intensive care, and the likely long-term sequelae. Patients, and carers, are often just starting to adjust to 'life after ICU' at the time support is most lacking or least coordinated. This contrasts markedly with another life-threatening and changing condition-cancer. In most countries, cancer survivors are supported through a range of services, charities, and support structures during their treatment and aftercare. This is widely accepted as important in health policy and often well-funded by healthcare providers and charities. Recent explorations of ICU survivorship indicate many similarities to cancer, including the very personal journey each person experiences, the individual time frame in which it occurs, and the need for information and peer support [6-8]. Yet critical illness survivorship tends to be viewed in generic terms with 'one size fits all' models of support-perhaps the same situation faced by cancer survivors in previous decades.

In recent years, interest and research into ICU aftercare have increased substantially. The most widely used service model is a 'post intensive care clinic' 2-3 months after hospital discharge. This 'biomedical' service model enables systematic assessment and triage for further specialist care, but its clinical and cost-effectiveness are unproven $[9,10]$. In addition, around a quarter of patients are likely to have already experienced unscheduled rehospitalisation by this time, questioning whether this is the optimum time for support [11]. Alternative models include peer support groups, hospitalbased programmes, telephone consultations and hybrid approaches. None of these have a convincing evidence base [10]. It seems likely that to provide the personalised support that patients require, we should first better

\section{6 Springer}


understand their perspective and then design aftercare to address unmet need, rather than impose our pre-conceived beliefs. We also need to better understand how post-ICU activities can improve what we do at the start of the survivor journey-within the ICU.

In this edition of Intensive Care Medicine, Haines and colleagues present important insights into how one approach to ICU aftercare activities could improve inICU care [12]. The work was part of THRIVE, a programme coordinated by the Society of Critical Care Medicine that provides resources and education for ICU patient survivors and their families through voluntary participation by interested groups and centres. The researchers used focus groups and telephone interviews to capture the views of THRIVE collaborators who use post-ICU clinics and peer support approaches. The novelty of this study was that, rather than focus on the impact on survivors, they asked participants to describe how they thought ICU clinics and peer support groups can improve in-ICU care and services. Strengths of the study included access to a broad range of settings and multidisciplinary team members, which included groups in the United States, United Kingdom, and Australia. The researchers used qualitative data collection and framework analysis to explore the data, an inductive non-hypothesis-driven approach which aims to pinpoint, examine, and record patterns (or "themes") within the data acquired to describe the issue of interest. Although the data obtained are limited to the views of those interviewed, which might not represent all contexts and settings, the approach aims to provide an unbiased interpretation of complex information.

The authors described a 'construct' - mechanisms driving improvement in the ICU-that comprised five major themes. Three of these were 'organisational', namely: identifying new targets for ICU quality improvement or education programs; creating a new role for survivors or their families in the ICU, for example as volunteers; and inviting critical care providers to the post-ICU program to educate, sensitize, and motivate them. Two themes were 'intra-clinical', namely: changing clinicians' understanding of patient experience to improve their care; and, improving morale and meaningfulness of ICU work by closing feedback loops regarding patient and family outcomes. As the authors highlight, these themes include issues important to the future of critical care medicine, such as maintaining morale, and preventing clinical burnout and stress. They also provide novel insights into how to iteratively improve care using quality improvement methodology, an approach that is a proven success story in other areas of our care, such as sedation, infection control, and early mobilisation. The improvement mechanisms described could be used to provide more consistent approaches to developing and integrating post-ICU services into current organisational designs and workloads. Importantly, they can also be used as the basis of a theory for how post-ICU interventions may improve quality and outcomes that could be tested in future research.

Given the largely 'no effect' results from most of the clinical trials undertaken so far to evaluate the effect of a range of post-ICU interventions [13, 14], this study represents important progress in the field. The possible sequelae, otherwise, is dis-investment in post-ICU services. It is also refreshing to see a study using qualitative methodology published in a high-quality medical specialty journal with wide reach and impact, especially when the findings have potential to improve the quality of ICU services.

\section{Author details}

${ }^{1}$ Chair of Critical Care, Edinburgh University, Edinburgh, UK. ${ }^{2}$ Head, Anaesthetics, Critical Care and Pain Medicine, University of Edinburgh, Edinburgh, UK. ${ }^{3}$ Royal Infirmary of Edinburgh, 51 Little France Crescent, Edinburgh EH16 4SA, UK. ${ }^{4}$ Plymouth University Clinical School, Plymouth, UK. ${ }^{5}$ University of Plymouth, Drake Circus, Plymouth, Devon PL4 8AA, UK.

\section{Compliance with ethical standards}

\section{Conflicts of interest}

On behalf of all authors, the corresponding author states that there is no conflict of interest.

\section{Publisher's Note}

Springer Nature remains neutral with regard to jurisdictional claims in published maps and institutional affiliations.

Received: 20 May 2019 Accepted: 23 May 2019

Published online: 13 June 2019

\section{References}

1. Needham DM, Davidson J, Cohen H, Hopkins RO, Weinert C, Wunsch H, Zawistowski C, Bemis-Dougherty A, Berney SC, Bienvenu OJ, Brady SL, Brodsky MB, Denehy L, Elliott D, Flatley C, Harabin AL, Jones C, Louis D, Meltzer W, Muldoon SR, Palmer JB, Perme C, Robinson M, Schmidt DM, Scruth E, Spill GR, Storey CP, Render M, Votto J, Harvey MA (2012) Improving long-term outcomes after discharge from intensive care unit: report from a stakeholders' conference. Crit Care Med 40:502-509

2. Rawal G, Yadav S, Kumar R (2017) Post-intensive care syndrome: an overview. J Transl Intern Med 5:90-92

3. Cuthbertson BH, Roughton S, Jenkinson D, Maclennan G, Vale L (2010) Quality of life in the 5 years after intensive care: a cohort study. Crit Care (London, England) 14:R6

4. Lone NI, Gillies MA, Haddow C, Dobbie R, Rowan KM, Wild SH, Murray GD, Walsh TS (2016) Five-year mortality and hospital costs associated with surviving intensive care. Am J Respir Crit Care Med 194:198-208

5. Arulkumaran N, Reay H, Brett SJ (2016) Research priorities by professional background - a detailed analysis of the James Lind alliance priority setting partnership. J Intensive Care Soc 17:111-116

6. Kean S, Salisbury LG, Rattray J, Walsh TS, Huby G, Ramsay P (2017) 'Intensive care unit survivorship' - a constructivist grounded theory of surviving critical illness. J Clin Nurs 26:3111-3124 
7. Deacon KS (2012) Re-building life after ICU: a qualitative study of the patients' perspective. Intensive Crit Care Nurs 28:114-122

8. Pattison N, O'Gara G, Rattray J (2015) After critical care: patient support after critical care. A mixed method longitudinal study using email interviews and questionnaires. Intensive Crit Care Nurs 31:213-222

9. Cuthbertson BH, Rattray J, Campbell MK, Gager M, Roughton S, Smith A, Hull A, Breeman S, Norrie J, Jenkinson D, Hernandez R, Johnston M, Wilson E, Waldmann C (2009) The PRaCTICaL study of nurse led, intensive care follow-up programmes for improving long term outcomes from critical illness: a pragmatic randomised controlled trial. BMJ (Clinical research ed) 339:b3723

10. Schofield-Robinson OJ, Lewis SR, Smith AF, McPeake J, Alderson P (2018) Follow-up services for improving long-term outcomes in intensive care unit (ICU) survivors. Cochrane Database Syst Rev. https://doi. org/10.1002/14651858.CD012701.pub2

11. Lone NI, Lee R, Salisbury L, Donaghy E, Ramsay P, Rattray J, Walsh TS (2018) Predicting risk of unplanned hospital readmission in survivors of critical illness: a population-level cohort study. Thorax. https://doi. org/10.1136/thoraxjnl-2017-210822

12. Haines KJ, Sevin CM, Hibbert E et al (2019) Key mechanisms by which post-ICU activities can improve in-ICU care: results of the international THRIVE collaboratives. Intensive Care Med. https://doi.org/10.1007/s0013 4-019-05647-5

13. Wade DM, Mouncey PR, Richards-Belle A, Wulff J, Harrison DA, Sadique $M Z$, Grieve RD, Emerson LM, Mason AJ, Aaronovitch D, Als N, Brewin CR, Harvey SE, Howell DCJ, Hudson N, Mythen MG, Smyth D, Weinman J, Welch J, Whitman C, Rowan KM, Investigators ftPT (2019) Effect of a nurse-led preventive psychological intervention on symptoms of posttraumatic stress disorder among critically ill patients: a randomized clinical trial. JAMA 321:665-675

14. Kross EK, Pollak Kl, Curtis JR (2019) Addressing the psychological symptoms of critical illness: the importance of "Negative" trials in guiding next steps. JAMA 321:649-650 